\title{
Study on the marketing of rural tourism destination based on the internet perspective
}

\author{
Congxi Cheng, Yangyang Zhang*, Sha Luo, Wenjing Yang, Yulu Guo, Hanli Yu, and \\ Jinqian Kang
}

School of Management and Center for County Economic Development Research in Hubei, Wuhan Polytechnic University, Wuhan, China

\begin{abstract}
With the rapid development of the rural tourism in China, how to innovate and optimize the marketing mode and successfully achieve the marketing purpose is an urgent problem for the marketing of the rural tourism destination. The rapid development of Internet technology has provided new ideas for rural tourism destination marketing. Based on the analysis of the questionnaire results of rural tourists, this paper has proposed the optimization suggestions of rural tourism destination marketing from the Internet perspective. That is, building the information communication channel between rural tourism destinations and tourists based on the Internet, designing tourism products of the rural tourism destination on the basis of tourist characteristics of tourists and realizing the marketing optimization of rural tourism destinations with the help of Internet technology.
\end{abstract}

Keywords: Internet, Rural tourism destination, Marketing strategies.

\section{Introduction}

As early as 2016, the No 1 Central Document clearly put forward the development strategy of "Internet + modern agriculture". At the same time, China also began to vigorously develop rural tourism and leisure agriculture and encouraged rural areas to make full use of local superior resources, including traditional folk culture and pastoral views to build traditional leisure agriculture projects, protect the precious historical and cultural heritage and promote the prosperity of the local rural economy [1]. With the support and promotion of a series of preferential rural tourism policies, China's rural tourism has developed rapidly. More and more people began to have strong willingness to participate in rural tourism, and the development of rural tourism has broad prospects. However, limited by the information asymmetry, there are still many rural tourism consumption needs that have not been fully excavated. From the perspective of tourism consumption decisionmaking process, tourists choose a rural tourist destination first, and then choose the specific tourism projects of the destination. So the marketing effect of rural tourism destinations is

${ }^{*}$ Corresponding author: $\underline{z s b @ \text { whpu.edu.cn }}$ 
very important. Based on the analysis of the questionnaire survey results of rural tourists, this paper has learned about the marketing objects of rural tourism destinations, analyzed the tourism preferences of rural tourists, and put forward the optimization suggestions of rural tourism destination marketing from the perspective of the Internet.

\section{The influence of the Internet on the tourist behavior}

\subsection{Providing more options for tourists}

In the past, tourists went to a tourist destination mostly through travel advertisements or recommend of relatives and friends. With the rapid development of Internet information technology, tourists can easily and quickly have a detailed understanding of tourist destinations in surrounding areas or the country and even around the world, and can obtain comprehensive tourism information[2].The rich information and convenient information access methods of the Internet platform not only make tourists more actively collect and analyze tourism destination information[3], but also can better meet the needs of tourists for diversified and personalized tourism services.

\subsection{Stimulating the tourism demand of tourists}

Tourists can fully access to all kinds of information of tourist destinations through the Internet platform. Pictures and videos of tourists taken on weekends and holidays, especially from friends and relatives, can better stimulate their tourist behavior.

\subsection{Providing much more convenience for tourists}

The choice of tourist destinations often needs a lot of information, involving eating, living, travelling, visiting, shopping and entertaining. Through the Internet platform, tourists can easily and quickly get the information of the tourist destination. The Internet can not only provide more convenience for tourists, but also can effectively solve their worries [2].

\section{Tourism characteristics analysis of rural tourists}

This research has investigated the consumer groups of rural tourism, and conducted a random survey around the "Internet marketing of rural tourist destinations" by issuing questionnaires on the Internet. A total of 395 questionnaires were collected, and all of which were valid.

\subsection{Interest investigation of rural tourists}

On the question of "Are you interested in rural tourism?" $25.82 \%$ said "very interested", $36.71 \%$ said" interested ", $29.62 \%$ said" a little interested "and $7.85 \%$ said " not interested". That is, $91.15 \%$ of people are interested in rural tourism, although the degree of interest varies, and only $7.85 \%$ said that they are not interested in rural tourism (figure 1). The data shows that the interest of people in rural tourism is generally very large. How to transform the willingness of interest in rural tourism into the actual travel is the work of rural tourism destination marketing. 


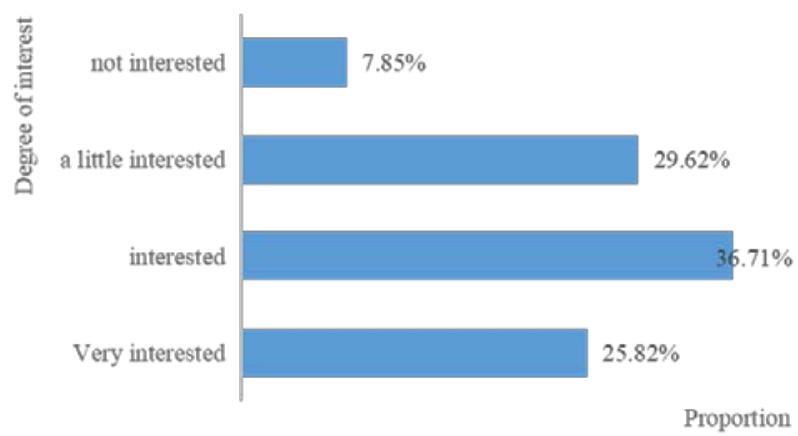

Fig. 1. The analysis of consumption preference of rural tourists.

(Source: questionnaire)

\subsection{Behavior characteristics of rural tourists}

According to the statistical results of the questionnaire survey, the main companions of tourists to rural tourism destinations are family members, friends, classmates, lovers and relatives. In terms of the time to travel to the countryside, $42.53 \%$ of tourists choose the small holiday (May Day, Tomb Sweeping Day, National Day, etc) to travel to the countryside, and $29.11 \%$ and $28.35 \%$ of tourists choose the winter and summer holidays and weekends respectively. During the small holiday, the pressure of rural tourism destinations to compete with other major tourism destinations will increase. In terms of the time spent in rural tourism destinations, 2-3 days is the most, accounting for $47.85 \%$, followed by one day and half a day, accounting for $45.06 \%$ in total. The time spent of tourists in one day and half a day is relatively large, which can reflect the small demand for accommodation in rural tourism. In terms of the total amount of consumption acceptable to rural tourism destinations, the survey results show that the total amount of consumption acceptable to tourists is $500-1000$ yuan, accounting for $41.77 \%$, followed by less than 500 yuan and 1000-1500 yuan, accounting for $25.57 \%$ and $17.97 \%$ respectively. That is to say, the total amount of consumption generally accepted by tourists is less than 1000 yuan, accounting for $67.34 \%$ of the total amount. This result shows that tourists' consumption budget for rural tourism is not high. In terms of the consumption expenditure of rural tourism, $86.33 \%$ of visitors say they spent mainly on catering, $70.89 \%$ say they spent mainly on accommodation, and around $30 \%$ of visitors say they spent money on transportation, shopping and entertainment. This result indicates that there is still a great space for the development of shopping and entertainment in rural tourism destinations.

\subsection{Consumption preference of rural tourists}

The questionnaire results show that (table 1) most tourists choose rural tourist destinations to participate in rural tourism activities because they want to get close to nature, enjoy the natural landscape, experience rural life, feel the local folk culture, stay away from the city and enjoy the quiet atmosphere. They prefer the rural tourism type of farming leisure, folk customs and traditional culture, and they are more likely to be attracted by leisure vacations, tasting special food, sightseeing projects. Visitors mainly focus on the following aspects of rural tourist destinations: First, beautiful natural landscape. Second, reasonable price. Third, unique catering. Fourth, perfect rest facilities. Fifth, the convenient transportation. These are important influencing factors for the choice of rural tourist destinations. 
Table 1. The analysis of consumption preference of rural tourists.

\begin{tabular}{lrl}
\hline Survey indicators & Degree or importance ranking (Top content is more important) \\
\hline $\begin{array}{l}\text { Reasons for } \\
\text { choosing get close to nature, enjoy the natural landscape; experience rural life, feel }\end{array}$ \\
$\begin{aligned} & \text { tourist destinations } \text { local folk culture; get away from the city noise, enjoy quiet atmosphere; } \\
& \text { for } \text { chat, walk and kill time; visit the surrounding attractions; increase } \\
& \text { activities tourism } \text { knowledge and broad the horizons; participate in business activities and } \\
& \text { official meetings, inspect and communicate; find excitement or fun: It's } \\
& \text { trendy and rural tourism is more popular recently }\end{aligned}$ \\
\hline
\end{tabular}

Degree of interest rural leisure type, folk customs traditional culture type, village and ancient in the different town type, rural leisure and vacation type, agricultural production rural tourism types experience type, experience and sports type, agricultural science education type, health care and entertainment type, rural business club type

The attraction leisure vacation (boating, fishing, taking photos, taking the baths, etc.), evaluation of rural taste special food, sightseeing tour, fitness (mountaineering, cycling and tourism projects swimming, etc.), cultural activities (visiting historical sites, participating in folk activities, learning folk inheritance technology, etc.), accommodation experience (B \& B, inn, farm land, tent, motor home, etc.), experience farming activities, shopping experience (buying local products, agricultural products, etc.), couples interactive experience projects, parent-child activity experience projects

$\begin{array}{rr}\text { Importance } \quad \text { of } & \begin{array}{c}\text { beautiful natural landscape, reasonable price, unique flavor of catering, } \\ \text { perfect recreation facilities, convenient transportation, harmonious local } \\ \text { influencing the } \\ \text { feelings and folk customs, typical rural scenery, diversified experience } \\ \text { activities, characteristic rural culture, famous countryside }\end{array} \\ \text { tourist destinations } & \text { rural }\end{array}$

(Source: questionnaire)

\subsection{Marketing channels of rural tourism}

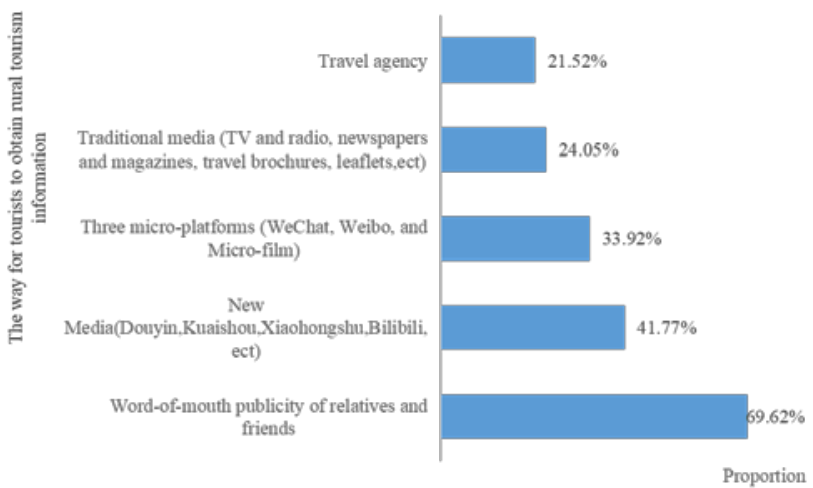

Fig. 2. Main channels for tourists to obtain information about rural tourist destinations

(Source: questionnaire).

The analysis shows (figure 2), the main way for rural tourism tourists obtain rural tourism information is recommended by relatives and friends, accounting for $69.62 \%$, followed by new media platforms and three micro platforms, accounting for $41.77 \%$ and $33.92 \%$ 
respectively. Traditional media and travel agencies also occupy a small proportion, $24.05 \%$ and $21.52 \%$ respectively. The results show that in the context of the prosperous development of the Internet, Internet marketing channels such as new media platforms and three micro platforms not yet to become the main way for tourists of rural tourism to obtain information related to tourist destinations.

\section{Optimization path of rural tourism destination marketing from the perspective of the Internet}

Rural tourism destination marketing is crucial to promoting the development of rural tourism industry, and it is closely related to their own preference for tourist to choose rural tourist destination [4]. Based on the analysis of rural tourists, the optimization path of rural tourism destination marketing is put forward as follows.

\subsection{Building an information communication channel between rural tourist destinations and tourists based on the Internet}

Marketing of rural tourism destination should pay more attention to the collection of tourists' information and accurately grasp the demand characteristics of tourists and their consumption trends through timely market research, so as to provide the basis and the right direction for the whole rural tourism destination marketing work. And then according to their own resource advantages and the actual situation of tourists, a variety of rural tourism and leisure products could be provided [5]. In the background of the rapid development of Internet technology, rural tourism destination marketing subjects should make full use of big data technology to analyze the behavior and demand of tourism consumers, and dynamically understand their consumption situation to grasp the consumption preferences. And it is important to maintain the continuous two-way communication between destinations and tourists [6], which could help to implement more specific marketing strategies and meet the needs of rural tourists.

\subsection{Designing tourism products of the rural tourism destination on the basis of tourist characteristics of tourists}

First, designing the rural tourism routes based on the behavior characteristics of rural tourists. According to the analysis of the behavior characteristics of rural tourists, most rural tourism tourists choose to travel 1-3 days together with their families, friends, classmates, lovers and relatives within the budget of 1,000 yuan. With this kind of characteristics, rural tourist routes should be designed with reasonable tourism order, reasonable tourism planning time and effective cost [7]. Besides, the design should pay attention to explore the shopping and entertainment projects in the destinations.

Second, building rural tourism types and designing projects based on the consumption preference of rural tourists. According to the analysis of the consumption preference of rural tourists, most tourists choose rural travel destinations because they want to get close to nature, enjoy the natural landscape, experience rural life, and feel the local folk culture. Therefore, with the root in the traditional history, agriculture, customs, rurality and other rural nature, rural tourism destination business should maintain the original local culture as far as possible to design rural tourism type and project [8]. The type and project could be about rural leisure, local culture, special food and sightseeing. The purpose of these are to let tourists experience and participate in rural life in the process of visiting and sightseeing, and feel and appreciate the unique charm of traditional rural culture in the activities. 
Starting from the five important factors of influencing the choice of tourists ' rural tourist destinations, the design should provide tourists with beautiful natural landscape, reasonable price, unique flavor, perfect rest facilities and convenient transportation.

\subsection{Realizing the marketing optimization of rural tourism destination with the help of Internet technology}

First, combining the use of rural tourism destination marketing tools. Integrated marketing of rural tourism destinations should comprehensively use a variety of marketing forms, and actively carry out multi-means, multi-angle and multi-dimensional integrated marketing for the target tourists. The rural tourism destination marketing subject should flexibly develop marketing activities in the form of integrated marketing in order to achieve better marketing results, expand its influence, attract more and more tourists to participate in local tourism activities, promote the sustainable and healthy development of rural tourism. That is "news push + network broadcast marketing + short video propagation + E-commerce publicity + knowledge sharing + social network + mobile App". Secondly, making full use of word-ofmouth market. Under the background of the Internet, tourists on the journey are increasingly like timely self-expression and experience sharing. Various sharing platforms provide channels for tourists to share pictures, shoot and upload short videos. Tourists can share, comment and forward them in real time, which is very conducive to the formation of word-of-mouth communication. Word-of-mouth marketing can effectively improve the authenticity of marketing products' content, and plays an increasingly important role in the decision-making process of tourists choosing rural tourism destinations [9]. What's more, the richness of word-of-mouth marketing can also solve the problem of insufficient official information release, and can effectively solve the dilemma of information asymmetry between rural tourist destinations and tourists [10]. In addition, rural tourism destinations can also build their own tourism e-commerce system. It can not only play a good complementary role in tourism destination marketing, but also have advantages of low cost and high efficiency, and can realize the resource integration and marketing channel integration of rural tourism destinations.

\section{Conclusion}

Nowadays, the rural tourism market competition has gradually transformed from the competition of scenic spots into the competition of tourist destinations, and rural tourism destination marketing is becoming more and more important. In the background of rapid development of Internet, this paper proposed the optimization suggestions of rural tourism destination marketing from the perspective of Internet. That is, building the information communication channel between rural tourism destinations and tourists based on the Internet, designing tourism products of the rural tourism destination on the basis of tourist characteristics of tourists and realizing the marketing optimization of rural tourism destinations with the help of Internet technology. These measures are designed to provide targeted and attractive rural tourism products to the target tourists, improve the pertinence and effectiveness of rural tourism destination marketing, so as to promote the overall development of tourism destinations, enhance the popularity of rural tourism destinations in the rural tourism market, enhance their competitiveness, and boost the vigorous development of rural tourism.

Support from 2019 University Practical Education Characteristic Project in Hubei Province: The Model Exploration of Rural Tourism Integration's Promoting Rural Revitalization and Poverty Alleviation (2019SJJPA2001). 


\section{References}

1. Zhang Qian. Research on the Optimization Strategy of New Media Marketing for Rural Tourism in the Internet Era [J]. China Management Information Technology, 2020, 23(20): 147-148.

2. Yang Yi-ju. Research on the Current Situation and Countermeasures of Rural Tourism Development in the Era of Shared Economy [J]. Journal of Changjiang Engineering Vocational and Technical College, 2021, 38(01):71-74.

3. Wei Wei. Research on Integrated Marketing of Urban Tourist ination under New Media Environment [J]. Business and Economic Research, 2021, (04):83-85.

4. Huang Juan. Research on the Recommendation Strategy of Rural Tourist Destination Based on the User Preferences [J]. Agricultural economy, 2021, (01):49-51.

5. $\mathrm{Xu} \mathrm{Lu}$. Research on Marketing Strategy of Rural tourist destinations [J]. Journal of Zhongzhou University, 2016, 33(01):15-18.

6. Guo Liping. Travel ination New Media Integrated Marketing Communication Research [J]. Journal, 2020, (05): 142-144.

7. Zhong De-shen; Hu Yue-fen. Preliminary Research on the Design of Oujiang Lian Cultural Tourism Line under the Background of Rural Revitalization [J]. Contemporary Tourism, 2020, (Z2):38-39+42.

8. Zhang Xiang-yun. "Five-in-One" Marketing Model and Its Realization in Rural Tourism [J]. Social scientists, 2018, (09):89-96.

9. Chen Hui-sha. Research on Internet Word-of-Mouth Marketing of Tourist Destination Based on 5T Theory [J]. Technology Economy Market, 2015, (07):58-60.

10. Wen Tong. Individual Travel Marketing Based on Web Communities [J]. Social scientists, 2009, (02): 99-102. 